\title{
R/R Genotype of Human Paraoxonase (PON1) is More Protective against Lipoprotein Oxidation and Coronary Artery Disease in Japanese Subjects
}

\author{
Kenichi Kuremoto, Yoshiro Watanabe, Hirotoshi Ohmura, Kazunori Shimada, Hiroshi Mokuno, \\ and Hiroyuki Daida
}

Department of Cardiology, Juntendo University School of Medicine, Tokyo, Japan.

\begin{abstract}
Human paraoxonase (PON1) is an high-density lipoprotein (HDL) -associated enzyme that is proposed to protect against the oxidation of lipoproteins. Recently, the association of coronary artery disease (CAD) and PON1 activity was reported. Furthermore, the $\mathrm{R} / \mathrm{R}$ genotype of PON1 has been related to the risk for CAD. In this study we investigated the PON1 genotype and susceptibility to lipoprotein oxidation to elucidate the contribution of PON1 to atherosclerosis in Japanese subjects. We studied 179 patients who underwent coronary angiography and their PON1 genotypes were determined. Lipoproteins were obtained from a patient's blood after at least 12 hours fasting and were separated with sequential ultracentrifugation. We analyzed the thiobarbituric acid reactive substances (TBARS) and continuously monitored the copper-induced oxidation three genotype groups. Genotype frequencies of $Q / Q, Q / R$, and $R / R$ were $21.2 \%, 36.9 \%$, and $41.9 \%$, respectively. PON1 polymorphism clearly determined the lipid oxidation. The R/R genotype of PON1 had significantly lower levels of plasma and HDL TBARS and significantly retarded the initiation of oxidation in HDL and low-density lipoprotein (LDL). The $R / R$ genotype was related to the lower prevalence of CAD. The PON1 genotype clearly determined the oxidative modification of lipoproteins and may play a role in the pathogenesis of atherosclerosis via its protective effect against lipoprotein oxidation in Japanese subjects. J Atheroscler Thromb, 2003; 10: 85-92.
\end{abstract}

Key words: PON1, Lipoprotein oxidation, Coronary artery disease

\section{Introduction}

Oxidative stress has an important role in numerous disease processes, in particular, the oxidation of lipoproteins is considered to be the main initiating factor of atherosclerosis and the aggravating factor for advanced atherosclerotic lesions. In vitro studies, oxidized lipoproteins such as oxidized low-density lipoprotein (LDL) induce the endothelial cell (EC) injury, monocyte and macrophage activation, smooth muscle cell (SMC) proliferation and foam cell formation $(1,2)$. Recently, it was suggested that high-density

Address for correspondence: Yoshiro Watanabe, Department of Cardiology, Juntendo University School of Medicine, 2-1-1 Hongo, Bunkyo-ku, Tokyo 113-8421, Japan.

E-mail: yoshiro@med.juntendo.ac.jp

Received August 28, 2002.

Accepted for publication November 12, 2002. lipoprotein (HDL) has an antioxidant effect on LDL oxidation. In the interaction between LDL and HDL particles, peroxides in the LDL particles are transferred to HDL particles where antioxidant property neutralizes this oxidant. Some HDLassociated enzymes are involved in these processes, such as lecithin-cholesterol acyltransferase (LCAT), platelet-activating factor acetylhydrolase (PAF-AH), and paraoxonase. Each of these enzymes modulates the process of oxidation in different mechanisms in vitro.

Human paraoxonase (PON1) is an HDL-associated enzyme, it hydrolyzes organophosphates such as paraoxon, carbamates, and nerve gases, therefore it was initially investigated in the field of toxicology $(3,4)$. In particular, PON1 prevents the lipoprotein oxidation of HDL, preventing LDL oxidation by the antioxidant effect of $\mathrm{HDL}$ in vitro $(5-7)$. Lower paraoxonase activity in subjects with myocardial infarction was reported in a clinical study (8). The 
paraoxonase gene family is located on chromosome 7q21.322.1 and contains at least 3 members, including PON1, PON2, and PON3 (9-13). This polymorphic distribution of PON1 is determined by a single amino acid substitution at position 192 (Gln to Arg; Q/R192, Q corresponds to A genotype and $\mathrm{R}$ to $\mathrm{B}$ genotype, respectively) which is believed to exist near the enzymatically active site. PON1 genetic polymorphism may determine the enzymatic activity of PON1 representing the low activity isoform as Q (Gln192) and high activity isoform as R (Arg192) (12). Recently, the association of coronary artery disease (CAD) and the PON1 genotype was reported and, surprisingly, the R/R genotype with high enzymatic activity was related to high prevalence of CAD in Caucasians (14-16). Furthermore, the R/R genotype of PON1 has been reported to have a less protective effect on lipoprotein oxidation (17-19). However, the association of the PON1 genotype with antioxidant activity and the prevalence of CAD are still very controversial.

In this study we focused on the differences in antioxidant activity among the isoforms of the PON1 genotype, and its association with CAD prevalence in Japanese subjects to clarify the role of PON1 in the pathogenesis of atherosclerosis.

\section{Materials and Methods}

\section{Subjects}

We analyzed 179 consecutive patients, who underwent coronary angiography, to evaluate coronary artery disease. All the patients were Japanese and patients taking lipidlowering drugs and antioxidant vitamins were excluded. We defined the existence of coronary artery disease in this study as greater than $50 \%$ stenosis in one of the major segments of the coronary arteries. Informed consent was obtained from all subjects for this study.

\section{PON1 genotype analysis}

We obtained genomic DNA from a patient's, blood using a DNA Extractor WB Kit (Wako-Junyaku Co., Osaka, Japan). The isolated DNA was stored at $4^{\circ} \mathrm{C}$ until analysis. For the genotyping of PON1 we used polymerase chain reaction-restriction fragment length polymorphism (PCRRFLP) methods. We used the following primers described by Humbert et al. (12) for the 5'primer; 5'-TATTGTTG CTGTGGGACCTGAG-3', and for the 3'primer; 5'-CACGC TAAACCCAAATACATCTC-3'. PCR was performed with 30 cycles of amplification with annealing at $64^{\circ} \mathrm{C}$. PCR products were digested with Alwl restriction enzyme, separated by $2.5 \%$ agarose gel (NuSieve) electrophoresis, and visualized using of ethidium bromide. Genotype Q (GIn192) corresponded to a 99 bp and genotype R (Arg192) to 65 and 34 bp fragments.

\section{Clinical data}

Serum samples were obtained by venipuncuture with vacutainer tubes after at least 12 hours' fasting to measure the serum lipid profile of all patients. Serum total cholesterol (TC), HDL cholesterol, and triglycerides (TG) were measured by automated enzymatic methods. Apolipoprotein (apo) $\mathrm{A}-\mathrm{I}$ and apoB were measured by enzyme-linked immunosorbent assay (ELISA) method.

\section{Lipoprotein separation}

Lipoproteins were obtained from a patient's arterial at the time of coronary angiography blood via a catheter sheath into test tubes containing ethylenediaminetetraacetic acid (EDTA) disodium salt (final concentration 1.5 $\mathrm{mg} / \mathrm{ml}$ ). Plasma was immediately separated by centrifugation at 3,000 rpm for 10 minutes. To obtain LDL after removing very low-density lipoprotein (VLDL) using ultracentrifugation, samples taken from the bottom of the tubes were adjusted in density to $1.063 \mathrm{mg} / \mathrm{dl}$ with adequate potassium bromide $(\mathrm{KBr})$ solution and then ultracentrifuged at $100,000 \mathrm{rpm}$ for 4.5 hours at $15^{\circ} \mathrm{C}$ (OptimaTM TL Ultracentrifuge, Beckman TL100.4 rotor) as previously described by Havel et al. (20). After ultracentrifugation, LDL was removed and then HDL was obtained in same manner after adjusting the density to $1.21 \mathrm{mg} / \mathrm{dl}$, and it was ultracentrifuged at $100,000 \mathrm{rpm}$ for 6 hours at $15^{\circ} \mathrm{C}$. To remove $\mathrm{KBr}$ and EDTA, the stock samples were dialyzed over 18 hours against three changes of 2,000 ml volume of phosphatebuffered saline (PBS) with $\mathrm{pH} 7.4$ at $4^{\circ} \mathrm{C}$ in a dark place. After dialysis, the protein levels in each lipoprotein were measured by the Lowry method (21), and stock samples were stored at $4^{\circ} \mathrm{C}$ until used for all oxidation studies.

\section{TBARS}

Plasma and lipoproteins containing lipid peroxides levels were determined by thiobarbituric acid reactive substances (TBARS) in the plasma samples and in each lipoprotein fraction by using a lipoperoxide test kit (Wako-Junyaku Co., Osaka, Japan).

\section{Copper induced lipid oxidation}

Copper-induced lipid oxidation was measured during incubation at $37^{\circ} \mathrm{C}$ using $100 \mu \mathrm{g}$ of each lipoprotein fraction with $5 \mu \mathrm{M} \mathrm{CuSO}_{4}$ in a final volume of $1 \mathrm{ml} \mathrm{PBS}$. The diene production during copper-induced lipid oxidation was monitored by the change in $234 \mathrm{~nm}$ absorbance at 5 minute intervals for 240 minutes with a spectrophotometer (Beckman DU650). We calculated the lag time (min) from these results.

\section{Statistical analysis}

To compare CAD patients and patients without CAD by age, body mass index (BMI) and lipid levels, we used Student's $t$ test. Allele frequencies were determined by the gene counting method, and Hardy-Weinberg equilibrium was tested by the chi-square test. We used ANOVA for the proportional difference of PON1 genotype and age, 
BMI, lipids, TBARS, and lag time. Post-hoc analysis was performed in ANOVA analysis. For the nominal parameters we used chi-square analysis. A value of $p<0.05$ was considered statistically significant. All data were expressed as the mean \pm SD. The analysis was performed by StatView 4.5J and SPSS 5.1 for Macintosh computers.

\section{Results}

\section{Clinical characteristics}

CAD patients were older and, had a high prevalence of cigarette smoking and hypertension (HT) (Table 1). Clas-

Table 1. Baseline characteristics of patients with or without CAD.

\begin{tabular}{lccc}
\hline & $\begin{array}{c}\text { CAD }(+) \\
(n=124)\end{array}$ & $\begin{array}{c}\text { CAD (-) } \\
(n=55)\end{array}$ & P-value \\
\hline Age (y) & $62.9 \pm 9.4$ & $56.1 \pm 11.2$ & $<0.0001$ \\
BMI & $24.1 \pm 9.5$ & $22.9 \pm 4.2$ & 0.313 \\
TC & $191.5 \pm 32.3$ & $183.0 \pm 36.1$ & 0.114 \\
TG & $146.8 \pm 82.5$ & $120.1 \pm 60.7$ & 0.032 \\
HDL-C & $44.8 \pm 13.6$ & $53.2 \pm 18.2$ & 0.001 \\
apo A-I & $114.6 \pm 21.5$ & $125.0 \pm 27.1$ & 0.010 \\
apo B & $104.2 \pm 21.2$ & $96.3 \pm 21.7$ & 0.035 \\
Gender (male\%) & 87.5 & 65.0 & $<0.0001$ \\
DM (\%) & 32.2 & 18.2 & 0.055 \\
HT (\%) & 60.9 & 35.8 & 0.008 \\
SM (\%) & 71.4 & 63.0 & 0.031 \\
\hline
\end{tabular}

All data were indicated the mean \pm SD. $p<0.05$ was considered to be statistically significant.BMI: body mass index $\left(\mathrm{kg} / \mathrm{m}^{2}\right)$, TC: total cholesterol (mg/dl), TG: triglycerides (mg/ $\mathrm{dl}), \mathrm{HDL}-\mathrm{C}$ : high-density lipoprotein-cholesterol (mg/dl), apo A-I: apolipoprotein A-I (mg/dl), apo B: apolipoprotein B (mg/ dl), DM: diabetes mellitus, HT: hypertension, SM: current smoker. sical risk factors other than BMI, TC and the prevalence of diabetes showed a statistically significant difference.

\section{Genotype frequencies}

In the 179 patients, the genotype frequencies were $\mathrm{Q} / \mathrm{Q}$; $21.2 \%, Q / R ; 36.9 \%$, and $R / R ; 41.9 \%$. The allele frequencies were $Q(G \mid n) ; 0.40$ and $R(A r g) ; 0.60$. The prevalence of each allele was consistent with the Hardy-Weinberg equilibrium. The proportion of the $\mathrm{R}$ allele was 2 to 3 times higher than previously reported in Caucasian populations (14-16, 22-26), but identical to the Chinese population $(14,27)$ (Table 2).

\section{Genotypes and plasma lipid profile}

Among the genotypes there were no differences in the prevalence of classical risk factors and lipid levels (Table 3). Figure 1 shows the PON1 genotype and TBARS levels. Plasma and HDL TBARS were determined by the PON1 genotype. The R/R genotype of PON1 had significantly lower levels of plasma and HDL TBARS than the Q/Q genotype $(p<0.01)$, but TBARS values of VLDL and LDL did not

Table 2. Genotype and allele frequency of patient groups.

\begin{tabular}{cc}
\hline & Patients $(n=179)$ \\
\hline Genotype frequency & \\
$\mathrm{Q} / \mathrm{Q}$ & $21.2 \% \quad(38 / 179)$ \\
$\mathrm{Q} / \mathrm{R}$ & $36.9 \%(66 / 179)$ \\
$\mathrm{R} / \mathrm{R}$ & $41.9 \% \quad(75 / 179)$ \\
Allele frequency & \\
$\mathrm{Q}$ (GIn) & 0.40 \\
$\mathrm{R}$ (Arg) & 0.60 \\
\hline
\end{tabular}

$\mathrm{Q} / \mathrm{Q}$ : homozygous low activity genotype, $\mathrm{Q} / \mathrm{R}$ : heterozygous genotype, R/R: homozygous high activity genotype.

Table 3. Classical coronary risk factors and lipid profile of patients with different genotypes.

\begin{tabular}{lccrc}
\hline & Q/Q & Q/R & R/R & P-value \\
\hline Age (y) & $59.6 \pm 9.9$ & $62.8 \pm 9.9$ & $59.6 \pm 11.7$ & 0.155 \\
BMI & $23.0 \pm 3.4$ & $22.9 \pm 2.8$ & $24.3 \pm 12.5$ & 0.585 \\
TC & $196.8 \pm 27.0$ & $185.0 \pm 33.1$ & $192.0 \pm 35.2$ & 0.258 \\
TG & $128.1 \pm 51.8$ & $141.8 \pm 62.0$ & $140.3 \pm 89.6$ & 0.708 \\
HDL-C & $50.8 \pm 15.6$ & $45.4 \pm 14.4$ & $47.7 \pm 16.6$ & 0.340 \\
apoA-I & $121.3 \pm 20.0$ & $113.5 \pm 24.8$ & $119.6 \pm 24.5$ & 0.298 \\
apoB & $102.1 \pm 22.9$ & $101.2 \pm 21.3$ & $102.8 \pm 21.9$ & 0.934 \\
Gender (male\%) & 9.5 & 82.1 & 75.0 & 0.581 \\
DM (\%) & 28.6 & 37.5 & 26.2 & 0.432 \\
HT (\%) & 51.6 & 46.7 & 60.0 & 0.308 \\
SM (\%) & 71.8 & 74.2 & 75.7 & 0.904 \\
\hline
\end{tabular}

All data were indicated the mean \pm SD. $p<0.05$ was considered to be statistically significant. BMl: body mass index $\left(\mathrm{kg} / \mathrm{m}^{2}\right)$, TC: total cholesterol (mg/dl), TG: triglycerides (mg/dl), HDL-C: high-density lipoprotein-cholesterol (mg/dl), apoA-l: apolipoprotein A-I (mg/dl), Apo B: apolipoprotein B (mg/dl), DM: diabetes mellitus, HT: hypertension, SM: current smoker. 


\section{A. Plasma}

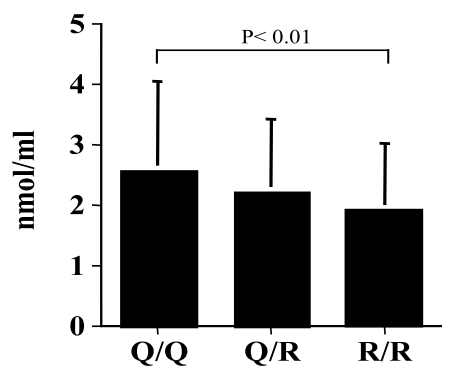

B. LDL

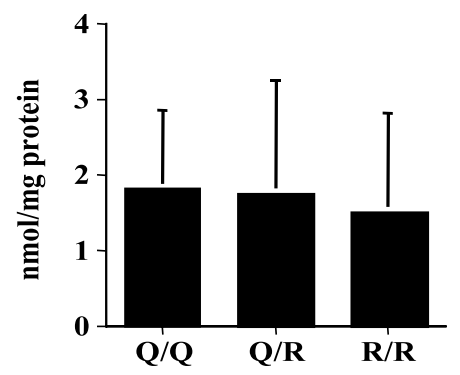

C. VLDL

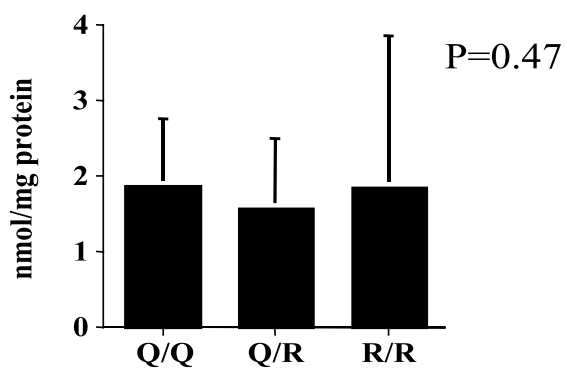

D. HDL

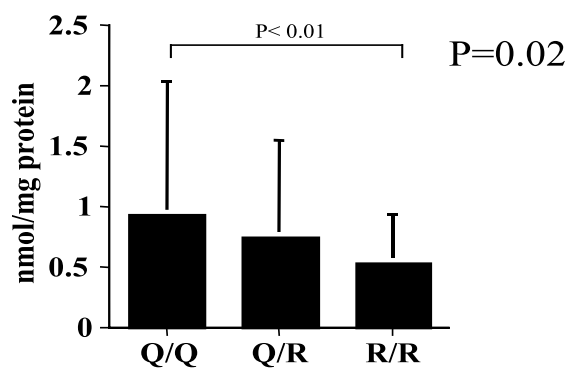

Fig. 1. PON1 genotype and TBARS values of plasma (A), LDL (B), VLDL (C), and HDL (D). Plasma and lipoproteins containing lipid peroxides levels were determined using a lipoperoxide test kit. We used chi-square analysis for the nominal parameters. $p<0.05$ was considered to be statistically significant.

A. VLDL

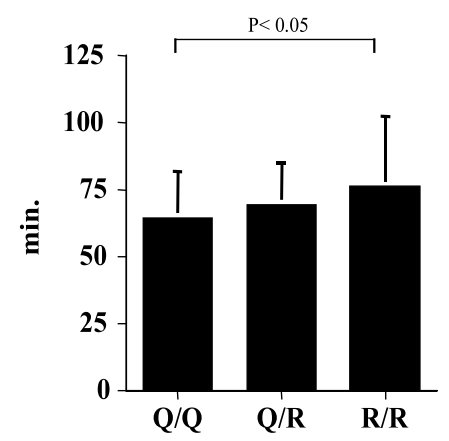

$\mathrm{P}=0.13$
B. LDL

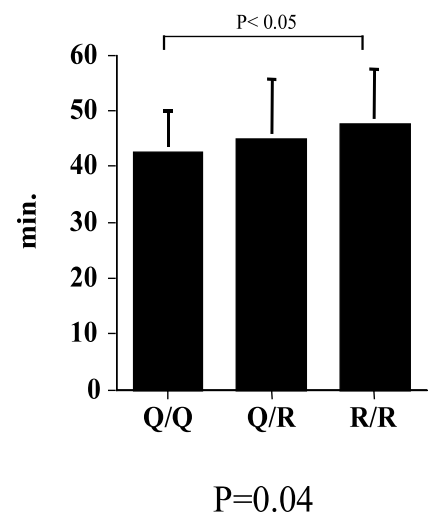

C. HDL

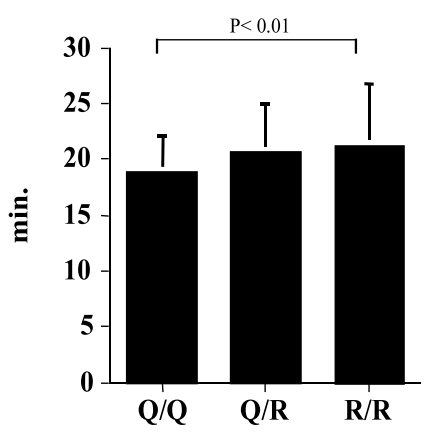

$\mathrm{P}=0.04$

Fig. 2. PON1 genotype and lag time of VLDL (A), LDL (B), and HDL (C). The calculated lag time resulting from copper-induced lipid oxidation. Copper-induced lipid oxidation was measured during incubation at $37^{\circ} \mathrm{C}$ and was then analyzed by a spectrophotometer with detection at $234 \mathrm{~nm}$. We used chi-square analysis for the nominal parameters. $p<0.05$ was considered to be statistically significant. 
differ. Figure 2 shows the calculated lag time results from copper induced lipoprotein oxidation. The HDL lag time was significantly different among the genotypes. The R/R genotype showed significantly retarded initiation of oxidation compared with the $Q / Q$ genotype $(p<0.01)$. The lag time of VLDL and LDL had a similar tendency to HDL. The $\mathrm{R} / \mathrm{R}$ genotype also showed significantly retarded initiation of oxidation compared with the $Q / Q$ genotype in VLDL and $\operatorname{LDL}(p<0.05$, respectively).

\section{Polymorphisms and incidence of coronary artery disease}

Table 4 shows the genotype distribution of the PON1 polymorphism in CAD patients. The genotype distribution was significantly different between CAD patients and patients without CAD ( $p=0.02)$. In patients without CAD, the frequency of the $R / R$ genotype was significantly higher than the other genotypes (R/R; 56\%, Q/Q; $20 \%$, Q/R; $24 \%$, respectively; $p<0.05)$.

\section{Discussion}

In this study, we evaluated the PON1 genotype and susceptibility to oxidation of lipoproteins to elucidate the contribution of PON1 to atherosclerosis in Japanese subjects. In particular we focused on the differences of antioxidant activity using TBARS and lag time measurements among the isoforms of the PON1 genotype and we clearly demonstrated that the $\mathrm{R} / \mathrm{R}$ genotype had higher activity against HDL and LDL oxidation, subsequently having the lowest prevalence of CAD, compared with other genotypes. These results indicated that PON1 could be considered a determinant factor of lipoprotein oxidation and CAD development.

PON1 is an esterase showing polymorphic enzymatic activity affected by the PON1 genotype. In general, the $\mathrm{R} / \mathrm{R}$ genotype has high paraoxonase activity and the $\mathrm{Q} / \mathrm{Q}$ genotype has low activity. However, the active site of PON1 for antioxidation is reported to be related cysteine at position 283 of the amino acid sequence (17), which is different from the enzymatic active site. Therefore, the antioxidant capacity of PON1 is not always identical to PON1 enzymatic activity and the PON1 genotype, which may cause the controversial association of PON1 with CAD. It is clear that HDL-associated PON1 has antioxidant activity against $\mathrm{HDL}$ itself, leading to the protective effect of HDL against LDL oxidation indirectly. Moreover,

Table 4. Genotype distribution in patients with or without CAD.

\begin{tabular}{lll}
\hline & CAD (-) & CAD (+) \\
\hline$Q / Q$ & $11(20 \%)$ & $28(22 \%)$ \\
$Q / R$ & $13(24 \%)$ & $53(43 \%)$ \\
$R / R$ & $31(56 \%)$ & $43(35 \%)$ \\
\hline
\end{tabular}

several studies have reported that PON1 was able to inhibit copper-induced lipid oxidation in LDL (5) and to hydrolyze long-chain oxidized phospholipids isolated from oxidized LDL (6). In addition, recent studies have also reported that specific non-competitive inhibitors of PON1 were able to suppress its protection against the oxidation both of HDL and LDL (28). Regarding the association of the PON1 genotype with lipoprotein oxidation, some studies have reported that the $R / R$ genotype was less efficient at retarding the oxidation of LDL than the $Q / Q$ genotype (17-19). However, in our study, the R/R genotype significantly retarded the initiation of oxidation in HDL and LDL and suppressed the oxidative production of plasma and HDL. One explanation for the antioxidant activity of PON1 associated with HDL against LDL oxidation, is that PON1 causes metabolic changes which may modify the composition or structure of LDL, resulting in changed levels of vitamin $E$ and fatty acids and leading to LDL resistance against oxidation without the presence of HDL. Although a few studies have examined the direct effect of PON1 against LDL oxidation and its association with the PON1 genotype, the association of antioxidant activity of PON1 with the PON1 genotype is still controversial. In order to clarify this inconsistent association, an experiment should be performed to assess the antioxidant activity of $\mathrm{HDL}$ from PON1 knockout mice in which recombinant $R / R$ or Q/Q PON1 genotype mutants are incorporated.

Furthermore, the association of the PON1 genotype with CAD prevalence is also inconsistent in clinical studies. In recent basic research, Shih et al. demonstrated that reduced serum levels of PON1 activity are associated with higher lipoprotein oxidation and more pronounced atherosclerotic lesions in the PON1 knockout mice and PON1 knockout/apoE knockout mice model $(29,30)$. This suggests that reduced PON1 expression may increase the risk for CAD. In our clinical study, the R/R genotype of PON1 showing high antioxidant activity had a lower prevalence of CAD in Japanese subjects, compared with the other genotypes, which is the very compatible result with the PON1 genotype, its antioxidant activity, and CAD. However, most studies have shown that the R/R genotype of PON1 had a higher prevalence of CAD in Caucasians (14-16) and Japanese (31-33) and some studies have failed to find such a relationship $(14,24-27,34)$. Mackness et al. (35) reported the meta-analysis of the PON1 genotype and the prevalence of CAD. They concluded that PON1 activities toward paraoxon and PON1 concentration are lower in patients with CAD than the control subjects regardless of the PON1 genotype. This indicates that PON1 genetic polymorphisms may determine neither the antioxidant activity of PON1, nor the enzymatic activity and concentration of PON1. Recently, Suehiro et al. (36) reported that PON1 concentration was decreased but paraoxonase and arylesterase activities were increased in hemodialyzed patients with no significant as- 
sociation of serum the PON1 concentrations with the PON1 genotype.

Finally, the association of the PON1 genotype with antioxidant activity and the prevalence of CAD are still very controversial. However, some clinical studies in Caucasians have demonstrated that the R/R genotype had lower antioxidant activity of PON1 leading to a higher prevalence of CAD (17-19). Our results totally oppose these results, showing that the $\mathrm{R} / \mathrm{R}$ genotype has a protective effect against oxidation of HDL and LDL and development of CAD. Although previous studies have not examined the association of antioxidant activity and genotype of PON1 with CAD simultaneously, this discrepancy may result from some factors affecting PON1 activity, such as race, Diabetes mellitus, and smoking. In contrast to most studies in Caucasians, all our subjects were Japanese undergoing coronary angiography to evaluate CAD without taking lipid-lowering drugs. In the analysis of the PON1 genotype in diabetic patients, one study demonstrated increased intima-media thickness (IMT) on carotid artery echogram in the $Q / Q$ genotype (37), which is consistent with our results, but the other study showed no association between the IMT and PON1 genotypes (38). Another possibility related to factors affecting the antioxidant activity of PON1 is smoking. James et al. (39) reported that cigarette smoking is independently associated with significant decreases in serum PON1 activities and concentrations, diminishing its antioxidant capacity. Among smokers, the $Q / Q$ genotype at low risk for CAD has been demonstrated to have increased the susceptibility to CAD (40). In our study, two thirds of the subjects were current smokers, therefore we analyzed our data in smokers and nonsmokers separately. However, we could find no association of its antioxidant activity with the PON1 genotype.

Our study was a relatively a small sample size, therefore our results were insufficient to reach conclusive results. Further studies are needed to clarify these complex issues.

In conclusion, the PON1 genotype clearly determined the oxidative modification of lipoproteins and may play a role in the pathogenesis of atherosclerosis via its protective effect against lipoprotein oxidation in Japanese subjects.

\section{References}

(1) Steinberg D, Parthasarathy S, Carew TE, Khoo JC, and Witztum JL: Beyond cholesterol: modifications of low-density lipoprotein that increase its atherogenicity. N Engl J Med, 320: 915-924, 1989

( 2 ) Witztum JL and Steinberg D: Role of oxidized low density lipoprotein in atherogenesis. J Clin Invest, 88: 1785-1792, 1991

( 3 ) Tafuri J and Roberts J: Organophosphate poisoning. Ann Emerg Med, 16: 193-202,1987

(4) Smolen A, Eckerson H W, Gan K N, Hailat N, and
LaDu BN: Characteristics of the genetically determined allozymic forms of human serum paraoxonase/ arylesterase. Drug Metab Dispos, 19: 107-112, 1991

( 5 ) Mackness Ml, Arrol S, and Durrington PN: Paraoxonase prevents accumulation of lipoperoxides in lowdensity lipoprotein. FEBS Lett, 286: 152-154, 1991

(6) Watson AD, Berliner JA, Hama SY, La Du BN, Faull KF, Fogelman AM, and Navab M: Protective effect of high density lipoprotein associated paraoxonase: inhibition of the biological activity of minimally oxidized low density lipoprotein. J Clin Invest, 96: 28822891, 1995

( 7 ) Mackness MI, Arrol S, Abbott C, and Durrington PN: Protection of low-density lipoprotein against oxidative modification by high-density lipoprotein associated paraoxonase. Atherosclerosis, 104: 129-135, 1993

( 8 ) McElveen J, Mackness MI, Colley CM, Peard T, Warner S, and Walker $\mathrm{CH}$ : Distribution of paraoxon hydrolytic activity in the serum of patients after myocardial infarction. Clin Chem, 32: 671-683, 1986

( 9 ) Mackness MI, Mackness B, Durrington PN, Connelly PW, and Hegele RA: Paraoxonase: biochemistry, genetics and relationship to plasma lipoproteins. Curr Opin Lipidol, 7: 69-76, 1996

(10) Mackness B, Durrington PN, and Mackness Ml: Human serum paraoxonase. Gen Pharmacol, 31: 329336, 1998

(11) Hegele RA: Paraoxonase genes and disease. Ann Med, 31: 217-224, 1999

(12) Humbert R, Adler DA, Disteche CM, Hassett C, Omiecinski CJ, and Furlong CE: The molecular basis of the human serum paraoxonase activity polymorphism. Nat Genet, 3: 73-76, 1993

(13) Mochizuki H, Scherer SW, Xi T, Nickle DC, Majer M, Huizenga JJ, Tsui LC, and Prochazka M: Human PON2 gene at 7q21.3: cloning, multiple mRNA forms, and missense polymorphisms in the coding sequence. Gene, 213: 149-157, 1998

(14) Sanghera DK, Saha N, Aston CE, and Kamboh MI: Genetic polymorphism of paraoxonase and the risk of coronary heart disease. Arterioscler Thromb Vasc Biol, 17: 1067-1073, 1997

(15) Ruiz J, Blanche H, James RW, Garin MC, Vaisse C, Charpentier G, Cohen N, Morabia A, Passa P and Froguel P: Gln-Arg192 polymorphism of paraoxonase and coronary heart disease in type 2 diabetes. Lancet, 346: 869-872, 1995

(16) Serrato $M$ and Marian AJ: A variant of human paraoxonase/arylesterase (HUMPONA) gene is a risk factor for coronary artery disease. J Clin Invest, 96: 3005-3008, 1995

(17) Aviram M, Billecke S, Sorenson R, Bisgaier C, Newton R, Rosenblat M, Erogul J, Hsu C, Dunlop C, and La Du B: Paraoxonase active site required for pro- 
tection against LDL oxidation involves its free sulfhydryl group and is different from that required for its arylesterase/paraoxonase activities: selective action of human paraoxonase allozymes $Q$ and $R$. Arterioscler Thromb Vasc Biol, 18: 1617-1624, 1998

(18) Mackness MI, Arrol S, Mackness B, and Durrington $\mathrm{PN}$ : Alloenzymes of paraoxonase and effectiveness of high-density lipoproteins in protecting low-density lipoprotein against lipid peroxidation. Lancet, 349: 851-852, 1997

(19) Mackness B, Mackness MI, Arrol S, Turkie W, and Durrington PN: Effect of the human serum paraoxonase 55 and 192 genetic polymorphisms on the protection by high density lipoprotein against low density lipoprotein oxidative modification. FEBS Lett, 423: 57-60, 1998

(20) Havel RJ, Eder HA, and Bragdon JH: The distribution and chemical composition of ultracentrifugally separated lipoproteins in human serum. J Clin Invest, 34: 1345-1353, 1955

(21) Lowry OH, Rosebrough NJ, Farr AL, and Randall RJ: Protein measurement with the Folin phenol reagent. J Biol Chem, 193: 265-275, 1951

(22) Garin MC, James RW, Dussoix P, Blanche H, Passa $\mathrm{P}$, Froguel P, and Ruiz J: Paraoxonase polymorphism Met-Leu54 is associated with modified serum concentrations of the enzyme. A possible link between the paraoxonase gene and increased risk of cardiovascular disease in diabetes. J Clin Invest, 99: 6266, 1997

(23) Sanghera DK, Aston CE, Saha N, and Kamboh MI: DNA polymorphisms in two paraoxonase genes (PON1 and PON2) are associated with the risk of coronary heart disease. Am J Hum Genet, 62: 3644, 1998

(24) Herrmann SM, Blanc H, Poirier O, Arveiler D, Luc G, Evans A, Marques-Vidal P, Bard JM, and Cambien $\mathrm{F}$ : The Gln/Arg polymorphism of human paraoxonase (PON 192) is not related to myocardial infarction in the ECTIM study. Atherosclerosis, 126: 299-303, 1996

(25) Antikainen M, Murtomaki S, Syvanne M, Pahlman $\mathrm{R}$, Tahvanainen $\mathrm{E}$, Jauhiainen $\mathrm{M}$, Frick $\mathrm{MH}$, and Ehnholm C: The Gln-Arg191 polymorphism of the human paraoxonase gene (HUMPONA) is not associated with the risk of coronary artery disease in Finns. J Clin Invest, 98: 883-885, 1996

(26) Ombres D, Pannitteri G, Montali A, Candeloro A, Seccareccia F, Campagna F, Cantini R, Campa PP, Ricci G, and Arca M: The Gln-Arg 192 polymorphism of human paraoxonase gene is not associated with coronary artery disease in Italian patients. Arterioscler Thromb Vasc Biol, 18: 1611-1616, 1998

(27) Ko YL, Ko YS, Wang SM, Hsu LA, Chang CJ, Chu $\mathrm{PH}$, Cheng NJ, Chen WJ, Chiang CW, and Lee YS:
The GIn-Arg 191 polymorphism of the human paraoxonase gene is not associated with the risk of coronary artery disease among Chinese in Taiwan. Atherosclerosis, 141: 259-264, 1998

(28) Aviram M, Rosenblat M, Bisgaier CL, Newton RS, Primo-Parmo SL, and La Du BN: Paraoxonase inhibits high-density lipoprotein oxidation and preserves its functions: a possible peroxidative role for paraoxonase. J Clin Invest, 101: 1581-1590, 1998

(29) Shih DM, Gu L, Xia YR, Navab M, Li WF, Hama S, Castellani LW, Furlong CE, Costa LG, Fogelman AM, and Lusis AJ: Mice lacking serum paraoxonase are susceptible to organophosphate toxicity and atherosclerosis. Nature, 394: 284-287, 1998

(30) Shih DM, Xia YR, Wang XP, Miller E, Castellani LW, Subbanagounder G, Cheroutre H, Faull KF, Berliner JA, Witztum JL, and Lusis AJ: Combined serum paraoxonase knockout/apolipoprotein E knockout mice exhibit increased lipoprotein oxidation and atherosclerosis. J Biol Chem, 275: 17527-17535, 2000

(31) Zama T, Murata M, Matsubara Y, Kawano K, Aoki N, Yoshino H, Watanabe G, Ishikawa K, and Ikeda Y: A 192 Arg variant of the human paraoxonase (HUMPONA) gene polymorphism is associated with an increased risk for coronary artery disease in the Japanese. Arterioscler Thromb Vasc Biol, 17: 35653569, 1997

(32) Odawara M, Tachi Y, and Yamashita K: Paraoxonase polymorphism (Gln192-Arg) is associated with coronary heart disease in Japanese noninsulin-dependent diabetes mellitus. J Clin Endocrinol Metab, 82: 2257-2260, 1997

(33) Imai $\mathrm{Y}$, Morita $\mathrm{H}$, Kurihara $\mathrm{H}$, Sugiyama $T$, Kato $\mathrm{N}$, Ebihara A, Hamada C, Kurihara Y, Shindo T, Oh-hashi $Y$, and Yazaki Y: Evidence for association between paraoxonase gene polymorphisms and atherosclerotic diseases. Atherosclerosis, 149: 435-442, 2000

(34) Suehiro T, Nakauchi $Y$, Yamamoto M, Arii K, Itoh H, Hamashige N, and Hashimoto K: Paraoxonase gene polymorphism in Japanese subjects with coronary heart disease. Int J Cardiol, 57: 69-73, 1996

(35) Mackness B, Davies GK, Turkie W, Lee E, Roberts $\mathrm{DH}$, Hill E, Roberts C, Durrington PN, and Mackness MI: Paraoxonase status in coronary heart disease are activity and concentration more important than genotype? Arterioscler Thromb Vasc Biol, 21: 14511457, 2001

(36) Suehiro T, Ikeda Y, Shiinoki T, Inoue M, Kumon $Y$, Itahara $\mathrm{T}$, and Hashimoto $\mathrm{K}$ : Serum paraoxonase (PON1) concentration in patients undergoing hemodialysis. J Atheroscler Thromb, 9: 133-138, 2002

(37) Sakai T, Matsuura B and Onji M: Serum paraoxonase activity and genotype distribution in Japanese patients with diabetes mellitus. Internal Medicine, 37 : 581-584, 1998 
(38) Cao H, Girard-Globa A, Serusclat A, Bernard S, Bondon P, Picard S, Berthezene F, and Moulin P: Lack of association between carotid intima-media thickness and paraoxonase gene polymorphism in non-insulin dependent diabetes mellitus. Atherosclerosis, 138: 361-366, 1998

(39) James RW, Leviev I, and Righetti A: Smoking is as- sociated with reduced serum paraoxonase activity and concentration in patients with coronary artery disease. Circulation, 101: 2252-2257, 2000

(40) Senti M, Aubo C, and Tomas M: Differential effects of smoking on myocardial infarction risk according to the GIn/Arg 192 variants of the human paraoxonase gene. Metabolism, 49: 557-559, 2000 